\title{
Predictors, complications and outcome of coronary artery bypass surgery in patients attending the cardiac center of Arar City, Northern Saudi Arabia
}

\author{
Bader Arar Shadad Alruwaili ${ }^{1}$, Malik Azhar Hussain ${ }^{2}$, Thamer Arar Shadad Alruwaili ${ }^{1}$, Taghreed Arar \\ Shadad Alruwaili ${ }^{1}$, Osama Mazha Mutkhan Alanazi ${ }^{1}$, Adel Turki D Alenezi ${ }^{1}$, Mohammed Khalil Al \\ Shakarah ${ }^{1}$, Saud Rteamy R Alanazi ${ }^{1}$, Anwar Khulaif B Alshammari ${ }^{1}$, Khawlah Hameed Alanazi ${ }^{1}$, \\ Abdulaziz Salamah Alanazi ${ }^{1}$, Ahmed Saud A Aldaghmi ${ }^{1}$, Abdullah Saad A Alanazi ${ }^{1}$, Munif Saleh \\ Alenezi $^{1}$ \\ ${ }^{1}$ Faculty of Medicine, Northern Border University, ${ }^{2}$ Surgery Department,College of Medicine. Northern Border \\ University.Arar Saudi Arabia
}

\begin{abstract}
Background: The increased incidence of cardiovascular disease between patients nowadays led to upsurge in the number of cardiac operations. After coronary artery bypass surgery, most patients remain free of symptoms for up to 15 years. The surgery also reduces the risk of heart attack and improves survival. Objective: to determine the predictors and outcome of coronary artery bypass surgery in patients attending the cardiac center in Arar, KSA all over the study period. Methods: The current study is a cross sectional study conducted during the period from September 2017 to March 2018. The current study included 72 individuals attending the cardiac center in Arar City. Collecting patients' data was conducted through interviewing the patients included in the study and reviewing their medical files. A predesigned questionnaire was used for data collection. Results: We found that $81.9 \%$ of cases were males, $61.1 \%$ aged from 30 to 39 years old, $34.4 \%$ of cases have a myocardial infraction as a clinical diagnosis before the operation, $25 \%$ had angina pain, and 50.0\% were smokers. Hyperlipidemia, chronic kidney disease, and chronic obstructive lung disease were found in $59.7 \%, 83.3 \%$ and $77.8 \%$ respectively. There were $41.6 \%$ who had postoperative arrhythmia, $13.9 \%$ had bacterial infection in the site of operation and another $13.9 \%$ had hypotension, $11.1 \%$ re-operated due to bleeding, and $6.9 \%$ got postoperative acute myocardial infarction. After 6 month of the operation, $69.4 \%$ of cases were quite good while recurrence of chest pain found in $12.5 \%$, heart failure in $2.8 \%$ and $8.3 \%$ died. There was significant association between outcome of cases after 6 months of operation and patients age $(\mathrm{P}<0.05)$ and all the dead cases were males. Conclusion: Our findings indicated that, among cardiac patients attending the cardiac center in Arar, KSA, the preoperative characteristics are suggestive of 30 to 39 years old males with myocardial infraction, angina pain, smokers, have hyperlipidemia, chronic kidney disease, and chronic obstructive lung disease is undergoing coronary artery bypass surgery. The death rate was low and $69.4 \%$ of cases were quite good.
\end{abstract}

Key words: Coronary artery bypass surgery, Indications, Complications, Outcome, Cardiac center of Arar City, Northern Saudi Arabia.

\section{INTRODUCTION}

As a result of continually improving surgical strategy and the technology which supports it, cardiac surgery is now possible in an increasingly high-risk population ${ }^{[1]}$. Crude mortality rates have often been used as an indicator of quality of care, but their value is limited without knowledge of the risk profile of the patients ${ }^{[2]}$.

Coronary artery bypass grafting (CABG) surgery performed for "Heart Attack", is the most common open-heart operation ${ }^{[3]}$. CABG is a technique that involves using an artery or vein from elsewhere in the body to bypass the blocked vessels, restoring adequate blood flow to the heart. The artery or vein is attached around the blockage, so that there is a new pathway for oxygenated blood to reach the heart muscle ${ }^{[4]}$.

The outcomes of CABG are excellent. Most patients remain free of symptoms for up to 15 years following surgery. The surgery also reduces the risk of heart attack and improves survival ${ }^{[4]}$.

As with any type of surgery, coronary artery bypass grafting (CABG) has risks in both short and long-term results. The risks of CABG include wound infection and bleeding, reactions to anesthesia, fever, pain, stroke, heart attack, or even death ${ }^{[5]}$.

Coronary artery surgery is now safer than ever before, owing to modern surgical techniques and pharmacological breakthroughs. Elderly patients, compared with patients of a younger age group, present for surgery with a greater burden of risk factors and reduced functional levels ${ }^{[6]}$.

In a study carried out by Weisel $\boldsymbol{e t}$ al. ${ }^{[7]}$ to identify the predictors of outcomes in patients undergoing $\mathrm{CABG}$. It was found that the preoperative risk factors were history of heart failure, increasing age, history of peripheral vascular disease and receiving aspirin before coronary artery bypass grafting; which was protective. 
In another study conducted by EscabíMendoza $\boldsymbol{e t}$ al. ${ }^{[8]}$ to describe the perioperative characteristics of the patients undergoing coronary artery bypass grafting in San Juan, Veterans Affairs Medical Center, and to determine the in-hospital and 30-day morbidity and mortality following CABG and identify adverse predictors for postoperative complications. It was reported that the associated illnesses included: hypertension $(95.6 \%)$, diabetes $(57 \%)$, past smoking (61\%), COPD (26\%), chronic renal insufficiency (11.5\%), cerebrovascular disease (CVD-20.6\%), disabling angina (78\%), 3-vessel coronary disease (75.8\%), significant left main stenosis (20\%), and nonelective surgical intervention (54\%). The most frequent primary complications were postoperative myocardial infarction (MI-4.8\%) and congestive heart failure $(4.8 \%)$. The 30 -day mortality was $1.2 \%$.

The aim of the study was to discuss the predictors and outcome of coronary artery bypass surgery in patients attending the cardiac center in Arar, KSA.

\section{PATIENT AND METHODS}

\section{Study design and participants:}

The current study is a cross sectional study conducted in the cardiac center in Arar city in the Northern Borders Province of the Kingdom of Saudi Arabia, during the period from September 2017 to March 2018. The current study included 72 individuals attending that center. The center was reviewed regularly during the study period, and the participants were selected by systemic random sampling procedure, and were invited to participate in the study and included in the study after taking an informed consent. Each person was interviewed separately, and their files were examined to collect the needed data and fill out the questionnaires. The cardiac center provides services in an acceptable atmosphere of both privacy and confidentiality. Exclusion criteria included patients who refused to participate in the study.

\section{Data Collection:}

Collecting patients' data was conducted through interviewing the patients included in the study and reviewing their medical files. A predesigned questionnaire was used for data collection, and included inquiries about sociodemographic data of the studied patients, smoking, hyperlipidemia, obesity, hypertension, diabetes mellitus, chronic kidney diseases, chronic obstructive lung disease, clinical diagnosis before the operation, acute post-operative complications and outcome of the cases after 6 months of operation.

\section{Ethical consideration:}

Written informed consent after explaining the purpose of the study was obtained from all patients who participated in the study. The questionnaires used in data collection were anonymous and confidentiality of data was assured.

\section{The statistical analysis:}

The statistical analysis was carried out using SPSS version 15. Sample characteristics were summarized as numbers and percentages for qualitative variables. Chi-Square test was used for testing the association between sociodemographic characters of the studied cardiac cases and conducting the coronary bypass operation. To show also the association between outcome of cases after 6 months of operation and sex, age and conditions before operation of the studied coronary bypass operation cases. A 5\% level was chosen as a level of statistical significance in all statistical tests used in the study.

\section{RESULTS}

Table (1) shows the socio-demographic characters of the studied coronary bypass operation cases. We found that $81.9 \%$ of cases were males, $61.1 \%$ aged from 30 to 39 years old, $68.1 \%$ were married, $51.4 \%$ reached university education and about $44.4 \%$ of them were working.

Table (2) illustrates the condition before operation of the studied coronary bypass operation cases. We found that most (34.4\%) of cases had a myocardial infraction as a clinical diagnosis before the operation, $25 \%$ had angina pain, $50.0 \%$ were smokers. Hyperlipidemia, chronic kidney disease, and chronic obstructive lung disease; were found in $59.7 \%, 83.3 \%$ and $77.8 \%$ respectively.

Table (3) shows the acute post-operative complications and outcome of the cases after 6 months of operation of the studied coronary bypass operation cases, there were $41.6 \%$ who had arrhythmia, $13.9 \%$ had bacterial infection in the site of operation and another $13.9 \%$ had hypotension, $11.1 \%$ re-operated due to bleeding, $6.9 \%$ got acute myocardial infarction. After 6 month of the operation, $69.4 \%$ of cases were quite good while recurrence of chest pain was found in $12.5 \%$, heart failure in $2.8 \%$ and $8.3 \%$ died.

There was significant association between all sociodemographic characters of the studied cardiac cases and conducting the coronary bypass operation $(\mathrm{P}<0.05)$ except the age $(\mathrm{P}>0.05)$. (Table 4) 
There was insignificant association between outcome of cases after 6 months of operation and sex and conditions before operation of the studied coronary bypass operation cases as angina pain, hyperlipidemia, smoking, obesity, hypertension, diabetes, family history of angina, renal insufficiency and COPD $(\mathrm{P}>0.05)$. While there was significant association between outcome of cases after 6 months of operation and patients age $(\mathrm{P}<0.05)$ and all the dead cases were males. (Table 5)

Table (1): Socio-demographic characters of the studied coronary bypass operation (with graft) cases in Arar, $2017(\mathrm{~N}=72)$.

\begin{tabular}{|l|c|c|}
\hline & No. & \% \\
\hline Sex & & \\
Female & 13 & 18.1 \\
Male & 59 & 81.9 \\
\hline Age group & & \\
60 or more & 9 & 12.5 \\
$30-39$ & 44 & 61.1 \\
$40-49$ & 13 & 18.1 \\
50-59 & 6 & 8.3 \\
\hline Marital status & 1 & \\
Widow & 22 & 1.4 \\
Single & 49 & 30.6 \\
Married & & 68.1 \\
\hline Educational level & 5 & \\
Primary & 5 & 6.9 \\
Preparatory & 15 & 6.9 \\
Secondary & 37 & 20.8 \\
University & 10 & 51.4 \\
Illiterate & & 13.9 \\
\hline Working status & 17 & \\
Private & 32 & 23.6 \\
Governmental & 17 & 44.4 \\
Not working & 6 & 23.6 \\
Retired & & 8.3 \\
\hline
\end{tabular}

Table (2): Condition before operation of the studied coronary bypass operation (with graft) cases in Arar, 2017.

\begin{tabular}{|l|c|c|}
\hline & No. & $\%$ \\
\hline Clinical diagnosis before the operation & 5 & \\
Peripheral arterial diseases & 24 & 6.9 \\
Myocardial Infarction & 8 & 33.3 \\
Unstable Angina pectoris is & 19 & 11.1 \\
Stable angina & 8 & 26.4 \\
Previous coronary artery grafting & 11.1 \\
Congestive heart failure & 8 & 11.1 \\
\hline Angina pain & & \\
No & 54 & 75.0 \\
Yes & 18 & 25.0 \\
\hline Family history of angina pectoris & & \\
No & 50 & 69.4 \\
Yes & 22 & 30.6 \\
\hline Hyperlipidemia & & \\
No & 43 & 59.7 \\
Yes & 29 & 40.3 \\
\hline Smoking & 29 & \\
Non smoker & 36 & 40.3 \\
Smoker & 7 & 50.0 \\
Ex-smoker & & 9.7 \\
\hline Obesity & 42 & 58.3 \\
No & 30 & 41.7 \\
\hline Yes & & \\
\hline Hypertension & 102 & 71.8 \\
No & 40 & 28.2 \\
\hline Yes & 111 & \\
\hline Diabetes mellitus & 31 & 78.2 \\
No & 60 & \\
Yes & 12 & 83.3 \\
\hline Chronic kidney diseases & 16 & 16.7 \\
No & & 77.8 \\
Yes & & \\
\hline Chronic Obstructive Lung Disease & & \\
No & & \\
Yes & & \\
\hline & & \\
\hline
\end{tabular}

Table (3): Acute post-operative complications and condition of the cases after 6 months of operation of the studied coronary bypass operation (with graft) cases in Arar, 2017.

\begin{tabular}{|l|c|c|}
\hline & No. & \% \\
\hline Acute post-operative complications & & \\
Re-operation due to bleeding & 8 & 11.1 \\
Bacterial infection in the site of the & 10 & 13.9 \\
operation & 10 & 13.9 \\
Hypotension & 5 & 6.9 \\
Myocardial infarction & 30 & 41.7 \\
Arrhythmia & 6 & 8.3 \\
Irregular heartbeat, bleeding & 9 & 12.5 \\
Bleeding & & \\
Condition of the cases after 6months of operation & 6 & 8.3 \\
Died & 5 & 6.9 \\
Arrhythmia & 9 & 12.5 \\
Recurrence of chest pain & 50 & 69.4 \\
Quite good & 2 & 2.8 \\
Heart failure
\end{tabular}

Table (4): Relationship between coronary bypass operation and socio-demographic characters of the studied cardiac cases, Arar, KSA.

\begin{tabular}{|c|c|c|c|c|}
\hline \multirow{2}{*}{ Variable } & \multicolumn{2}{|c|}{ Coronary bypass operation } & \multirow[b]{2}{*}{ Total $(n=144)$} & \multirow{2}{*}{$P$ value } \\
\hline & Yes $(n=72)$ & No $(n=72)$ & & \\
\hline \multicolumn{5}{|l|}{ Sex } \\
\hline \multirow{2}{*}{ Female } & 13 & 27 & 40 & \multirow{4}{*}{0.009} \\
\hline & $18.1 \%$ & $37.5 \%$ & $27.8 \%$ & \\
\hline \multirow{2}{*}{ Male } & 59 & 45 & 104 & \\
\hline & $81.9 \%$ & $62.5 \%$ & $72.2 \%$ & \\
\hline \multicolumn{5}{|l|}{ Age } \\
\hline \multirow{2}{*}{ 30-39 } & 44 & 49 & 93 & \multirow{8}{*}{0.434} \\
\hline & $61.1 \%$ & $68.1 \%$ & $64.6 \%$ & \\
\hline \multirow{2}{*}{$40-49$} & 13 & 15 & 28 & \\
\hline & $18.1 \%$ & $20.8 \%$ & $19.4 \%$ & \\
\hline \multirow{2}{*}{$50-59$} & 6 & 4 & 10 & \\
\hline & $8.3 \%$ & $5.6 \%$ & $6.9 \%$ & \\
\hline \multirow{2}{*}{$60+$} & 9 & 4 & 13 & \\
\hline & $12.5 \%$ & $5.6 \%$ & $9.0 \%$ & \\
\hline \multicolumn{5}{|l|}{ Marital status } \\
\hline \multirow{2}{*}{ Widow } & 1 & 0 & 1 & \multirow{8}{*}{0.031} \\
\hline & $1.4 \%$ & $.0 \%$ & $.7 \%$ & \\
\hline \multirow{2}{*}{ Single } & 22 & 32 & 54 & \\
\hline & $30.6 \%$ & $44.4 \%$ & $37.5 \%$ & \\
\hline \multirow{2}{*}{ Married } & 49 & 36 & 85 & \\
\hline & $68.1 \%$ & $50.0 \%$ & $59.0 \%$ & \\
\hline \multirow{2}{*}{ Divorced } & 0 & 4 & 4 & \\
\hline & $.0 \%$ & $5.6 \%$ & $2.8 \%$ & \\
\hline \multicolumn{5}{|c|}{ Educational level } \\
\hline \multirow{2}{*}{ Primary } & 5 & 0 & 5 & \multirow{10}{*}{0.042} \\
\hline & $6.9 \%$ & $.0 \%$ & $3.5 \%$ & \\
\hline \multirow{2}{*}{ Preparatory } & 5 & 4 & 9 & \\
\hline & $6.9 \%$ & $5.6 \%$ & $6.2 \%$ & \\
\hline & 15 & 16 & 31 & \\
\hline Secondary & $20.8 \%$ & $22.2 \%$ & $21.5 \%$ & \\
\hline & 37 & 48 & 85 & \\
\hline University & $51.4 \%$ & $66.7 \%$ & $59.0 \%$ & \\
\hline Uliterate & 10 & 4 & 14 & \\
\hline illiterate & $13.9 \%$ & $5.6 \%$ & $9.7 \%$ & \\
\hline Working status & & & & \\
\hline & 17 & 6 & 23 & \\
\hline Private & $23.6 \%$ & $8.3 \%$ & $16.0 \%$ & \\
\hline Governmental & 32 & 34 & 66 & \\
\hline Governmental & $44.4 \%$ & $47.2 \%$ & $45.8 \%$ & \\
\hline & 17 & 30 & 47 & 0.012 \\
\hline Not working & $23.6 \%$ & $41.7 \%$ & $32.6 \%$ & \\
\hline & 6 & 2 & 8 & \\
\hline Retired & $8.3 \%$ & $2.8 \%$ & $5.6 \%$ & \\
\hline
\end{tabular}


Table (5): Relationship between outcome of cases after 6 months of operation and sex, age and conditions before operation of the studied coronary bypass operation (with graft) cases in Arar, 2017 $(\mathrm{N}=72)$.

\begin{tabular}{|c|c|c|c|c|c|c|c|}
\hline \multirow{3}{*}{\begin{tabular}{|l} 
Sex \\
\end{tabular}} & \multicolumn{5}{|c|}{ Outcome of cases after 6 months of operation } & \multirow[b]{2}{*}{$\begin{array}{c}\text { Total } \\
(\mathrm{n}=72)\end{array}$} & \\
\hline & $\begin{array}{l}\text { Died } \\
(n=6)\end{array}$ & $\underset{(\mathbf{n}=5)}{\text { Arrhythmia }}$ & $\begin{array}{c}\text { Recurrence } \\
\text { of chest } \\
\text { pain }(n=9)\end{array}$ & \begin{tabular}{|l|} 
Quite \\
good \\
$(\mathrm{n}=50)$
\end{tabular} & \begin{tabular}{c|} 
Heart \\
failure $(n=2)$
\end{tabular} & & \\
\hline & \\
\hline \multirow{2}{*}{ Female } & 0 & 1 & 0 & 11 & 1 & 13 & \multirow{4}{*}{0.265} \\
\hline & $.0 \%$ & $20.0 \%$ & $.0 \%$ & $22.0 \%$ & $50.0 \%$ & $18.1 \%$ & \\
\hline \multirow{2}{*}{ Male } & 6 & 4 & 9 & 39 & 1 & 59 & \\
\hline & $100.0 \%$ & $80.0 \%$ & $100.0 \%$ & $78.0 \%$ & $50.0 \%$ & $81.9 \%$ & \\
\hline \multicolumn{8}{|l|}{ Age } \\
\hline \multirow{2}{*}{ 30-39 } & 3 & 3 & 7 & 31 & 0 & 44 & \multirow{8}{*}{0.008} \\
\hline & $50.0 \%$ & $60.0 \%$ & $77.8 \%$ & $62.0 \%$ & $.0 \%$ & $61.1 \%$ & \\
\hline \multirow{2}{*}{$40-49$} & 1 & 1 & 0 & 11 & 0 & 13 & \\
\hline & $16.7 \%$ & $20.0 \%$ & $.0 \%$ & $22.0 \%$ & $.0 \%$ & $18.1 \%$ & \\
\hline \multirow{2}{*}{$50-59$} & 1 & 0 & 1 & 2 & 2 & 6 & \\
\hline & $16.7 \%$ & $.0 \%$ & $11.1 \%$ & $4.0 \%$ & $100.0 \%$ & $8.3 \%$ & \\
\hline \multirow{2}{*}{$60+$} & 1 & 1 & 1 & 6 & 0 & 9 & \\
\hline & $16.7 \%$ & $20.0 \%$ & $11.1 \%$ & $12.0 \%$ & $.0 \%$ & $12.5 \%$ & \\
\hline Angina pain & & & & & & & \\
\hline $\mathrm{Ye}_{\mathrm{s}}$ & 2 & 2 & 0 & 14 & 0 & 18 & \\
\hline Yes & $33.3 \%$ & $40.0 \%$ & $.0 \%$ & $28.0 \%$ & $.0 \%$ & $25.0 \%$ & \\
\hline & 4 & 3 & 9 & 36 & 2 & 54 & 0.316 \\
\hline No & $66.7 \%$ & $60.0 \%$ & $100.0 \%$ & $72.0 \%$ & $100.0 \%$ & $75.0 \%$ & \\
\hline Hyperlipiden & & & & & & & \\
\hline & 3 & 0 & 5 & 20 & 1 & 29 & \\
\hline Yes & $50.0 \%$ & $.0 \%$ & $55.6 \%$ & $40.0 \%$ & $50.0 \%$ & $40.3 \%$ & \\
\hline & 3 & 5 & 4 & 30 & 1 & 43 & 0.335 \\
\hline No & $50.0 \%$ & $100.0 \%$ & $44.4 \%$ & $60.0 \%$ & $50.0 \%$ & $59.7 \%$ & \\
\hline Smoking & & & & & & & \\
\hline Smoler & 2 & 3 & 3 & 26 & 2 & 36 & \\
\hline Smoker & $33.3 \%$ & $60.0 \%$ & $33.3 \%$ & $52.0 \%$ & $100.0 \%$ & $50.0 \%$ & \\
\hline No & 4 & 1 & 5 & \begin{tabular}{|l|}
19 \\
\end{tabular} & 0 & 29 & 0610 \\
\hline Non-smoker & $66.7 \%$ & $20.0 \%$ & $55.6 \%$ & $38.0 \%$ & $.0 \%$ & $40.3 \%$ & 0.619 \\
\hline & 0 & 1 & 1 & 5 & 0 & 7 & \\
\hline Ex-smoker & $.0 \%$ & $20.0 \%$ & $11.1 \%$ & $10.0 \%$ & $.0 \%$ & $9.7 \%$ & \\
\hline Obesity & & & & & & & \\
\hline $\mathrm{y}_{\mathrm{s}}$ & 0 & 2 & 3 & 24 & 1 & 30 & \\
\hline Yes & $.0 \%$ & $40.0 \%$ & $33.3 \%$ & $48.0 \%$ & $50.0 \%$ & \begin{tabular}{|l|}
$41.7 \%$ \\
\end{tabular} & $02 \Delta$ \\
\hline No & 6 & 3 & 6 & \begin{tabular}{|l|}
26 \\
\end{tabular} & 1 & \begin{tabular}{|l|}
42 \\
\end{tabular} & 0.246 \\
\hline No & $100.0 \%$ & $60.0 \%$ & $66.7 \%$ & $52.0 \%$ & $50.0 \%$ & $58.3 \%$ & \\
\hline Hypertensior & & & & & & & \\
\hline$r_{1}$ & 3 & 3 & 5 & 21 & 0 & 32 & \\
\hline Yes & $50.0 \%$ & $60.0 \%$ & $55.6 \%$ & $42.0 \%$ & $.0 \%$ & \begin{tabular}{|l|}
$44.4 \%$ \\
\end{tabular} & 0603 \\
\hline No & 3 & 2 & 4 & $\begin{array}{ll}29 \\
\end{array}$ & 2 & 40 & 0.603 \\
\hline No & $50.0 \%$ & $40.0 \%$ & $44.4 \%$ & $58.0 \%$ & $100.0 \%$ & $55.6 \%$ & \\
\hline Diabetes & & & & & & & \\
\hline $\mathrm{y}_{0}$ & 2 & 2 & 3 & 18 & 2 & 27 & \\
\hline Yes & $33.3 \%$ & $40.0 \%$ & $33.3 \%$ & $36.0 \%$ & $100.0 \%$ & \begin{tabular}{|l|}
$37.5 \%$ \\
\end{tabular} & 0477 \\
\hline No & 4 & 3 & 6 & 32 & 0 & \begin{tabular}{|l|}
45 \\
\end{tabular} & 0.477 \\
\hline NO & $66.7 \%$ & $60.0 \%$ & $66.7 \%$ & \begin{tabular}{|l|}
$64.0 \%$ \\
\end{tabular} & $.0 \%$ & $62.5 \%$ & \\
\hline Family histo & & & & & & & \\
\hline$y_{e}$ & 1 & 2 & 3 & 14 & 2 & 22 & \\
\hline Yres & $16.7 \%$ & $40.0 \%$ & $33.3 \%$ & $28.0 \%$ & $100.0 \%$ & \begin{tabular}{|l|}
$30.6 \%$ \\
\end{tabular} & 0241 \\
\hline N & 5 & 3 & 6 & 36 & 0 & \begin{tabular}{|l|}
50 \\
\end{tabular} & 0.241 \\
\hline NO & $83.3 \%$ & $60.0 \%$ & $66.7 \%$ & $72.0 \%$ & $.0 \%$ & \begin{tabular}{|l|}
$69.4 \%$ \\
\end{tabular} & \\
\hline Renal insuffi & & & & & & & \\
\hline$y_{e c}$ & 3 & 1 & 2 & 6 & 0 & 12 & \\
\hline Yes & $50.0 \%$ & $20.0 \%$ & $22.2 \%$ & $12.0 \%$ & $.0 \%$ & \begin{tabular}{|l|}
$16.7 \%$ \\
\end{tabular} & 0.183 \\
\hline N & 3 & 4 & 7 & 44 & 2 & 60 & 0.183 \\
\hline INO & $50.0 \%$ & $80.0 \%$ & $77.8 \%$ & $88.0 \%$ & $100.0 \%$ & $83.3 \%$ & \\
\hline COPD & & & & & & & \\
\hline $\mathrm{Yec}_{\mathrm{e}}$ & 2 & 1 & 3 & 9 & 1 & 16 & \\
\hline Yes & $33.3 \%$ & $20.0 \%$ & $33.3 \%$ & $18.0 \%$ & $50.0 \%$ & $22.2 \%$ & \\
\hline No & 4 & 4 & 6 & 41 & 1 & 56 & 0.646 \\
\hline No & $66.7 \%$ & $80.0 \%$ & $66.7 \%$ & $82.0 \%$ & $50.0 \%$ & $77.8 \%$ & \\
\hline
\end{tabular}

\section{DISCUSSION}

The increased incidence of cardiovascular disease between patients nowadays led to upsurge in the number of cardiac operations. The aim of this study was to determine the indications and outcome of coronary artery bypass surgery in patients attending the cardiac center in Arar, KSA all over the study period. Our study included 72 patients, more than $80 \%$ of them were males. In our study the number of males underwent coronary bypass operation was 59 (81.9\%), which was much more than the number of females. Hypertension, diabetes mellitus and obesity were recorded in $44.4 \%, 37.5 \%$ and $41.7 \%$ of the cases presenting for coronary artery bypass operation respectively. EInazeer et al. ${ }^{[10]}$ found a higher percentage of diabetes mellitus $(60 \%)$ and hypertension (55\%) in their study. There is little doubt that our patients in Saudi Arabia differ in important respects from populations reported in western medical literature; as a much lower figures were reported than western populations ${ }^{[11,12]}$.

As regards the acute post-operative complications of cases, in our study, there were 41.6\% who had arrhythmia, $13.9 \%$ had bacterial infection in the site of operation and another 13.9\% had hypotension, $11.1 \%$ re-operated due to bleeding, $6.9 \%$ get acute myocardial infarction. It was reported that acute postoperative risks of $\mathrm{CABG}$ include wound infection and bleeding, reactions to anesthesia, fever, pain, stroke, heart attack, or even death ${ }^{[5]}$. While Escabí-Mendoza et al. ${ }^{[8]}$ reported that the most frequent primary complications were postoperative myocardial infarction (4.8\%) and congestive heart failure (4.8\%).

Regarding the outcome of cases after 6 months of operation was death in $6(8.3 \%)$ cases, arrhythmia in 5 cases, recurrence of chest pain in 9 $(12.5 \%)$ cases, heart failure in $2(2.8 \%)$ cases and the cases were stable and in improvement in 50 (69.4\%) cases. We recorded a significant correlation $(\mathrm{P}=$ 0.009 ) between sex and coronary bypass operation, however; there was no significant correlation between sex and the outcome of cases. It's obvious from table (5) that the operation outcome of females was much better than males. It is striking to observe that the high number of male cases was associated with a trend of higher mortality when compared with female gender. In another studies, a higher mortality rates was found in females when compared with males as reported by others ${ }^{[7]}$. Also Ascione et al. ${ }^{[9]}$ found a similar results in their study. We also found a significant correlation $(\mathrm{P}=0.008)$ between the outcome of the operation and the age group of the patients. Regarding to mortality rate, a study examining predictors of hospital mortality in patients undergoing $\mathrm{CABG}$ in acute myocardial analyzed that 
advanced age is a risk factor related to mortality ${ }^{[10]}$. Also Escabí-Mendoza et al. ${ }^{[8]}$ reported that the 30day mortality was $1.2 \%$.

\section{CONCLUSION AND RECOMMENDATIONS}

Our findings indicated that, among cardiac patients attending the cardiac center in Arar, KSA, in coronary artery bypass surgery, the preoperative characteristics are; 30 to 39 years old males with myocardial infraction, angina pain, smokers, have hyperlipidemia, chronic kidney disease, and chronic obstructive lung disease. The death rate was low and $69.4 \%$ of cases were quite good.

\section{REFERENCES}

1. Warner CD, Weintraub WS, Craver JM et al. (1997): Effect of cardiac surgery patient characteristics on patient outcomes from 1981 through 1995. Circulation, 96:1575-1579.

2. Roques F, Nashef S, Michel P et al. (1999): Risk factors and outcome in European cardiac surgery: analysis of the EuroSCORE multinational database of 19030 patients, Eur J Cardio-thorac., 15(6):816-22.

3. National Heart Centre Singapore (2018): Coronary Artery Bypass Grafting (CABG). https://www.nhcs.com.sg/patientcare/Condition sAndTreatments/Pages/bypass-CABG.aspx

4. Harris R, Croce B, Tian D (2013): Coronary artery bypass grafting. Ann Cardiothorac Surg., 2(4): 578-582.

5. National Heart, Lung, And Blood Institute (2018): Coronary Artery Bypass Grafting.

6. http://www.nhlbi.nih.gov/health/healthtopics/topics/cabg/

7. Natarajan A, Samadian S, Clark S (2007): Coronary artery bypass surgery in elderly people. Postgrad Med J., 83(977): 154-158.

8. Weisel $\mathrm{R}$, Nussmeier $\mathrm{N}$, Newman $\mathrm{M}$ et al. (2014): Predictors of contemporary coronary artery bypass grafting outcomes. The Journal of Thoracic and Cardiovascular Surgery,

9. 148(6):2720-2726

10. Escabí-Mendoza J, Acevedo J, Rucabado E et al. (2005): Early postoperative complications after coronary artery bypass grafting at the San Juan Veterans Affairs Medical Center. P R Health Sci J., 24(2):123-130.
11. Ascione R, Rees K, Santo $K$ et al. (2002): Coronary artery bypass grafting in patients over 70 years old: the influence of age and surgical technique on early and mid-term clinical outcomes. European Journal of CardioThoracic Surgery, 22(1):124-128.

12. Elnazeer O, David R, Elhammami $M$ et al. (2008): Coronary artery bypass grafting in elderly Saudi patients. Sudan Medical Journal, 44(3):29-34.

13. Milo E, Cynthia A, Donna $S$ (2002): Outcome and functional status in octogenarians and septuagenarians after cardiac surgery. Chest, 122(4):1309-1315.

14. Antony $J$, Acinapura $M$, Daniel $M$ et al. (1988): Coronary artery bypass in septuagenarians: analysis of mortality and morbidity. Circulation, 78(3):179-184. 